$\xi=-1$

\title{
Design and Analysis of Ultra Low-Profile ILA on a Rectangular Conducting Plane
}

\author{
Erfan Rohadi ${ }^{1}$, Mochammad Firdaus Ali ${ }^{2}$, Indrazno Siradjuddin² ${ }^{2}$ Awan Setiawan², Amalia Amalia ${ }^{2}$, \\ Yudhi Darmawan ${ }^{2}$ \\ ${ }^{1}$ State Polytechnic of Malang, Information Technology Department \\ ${ }^{2}$ State Polytechnic of Malang, Electrical Engineering Department \\ Jl. Soekarno Hatta No. 9, 65141, Malang, Indonesia \\ *Corresponding author E-mail: mfirdaus@polinema.ac.id
}

\begin{abstract}
The unbalanced fed ultra low profile inverted L antenna on a rectangular conducting plane is proposed and analyzed numerically and experimentally. By adjusting the length and height of inverted $\mathrm{L}$ antenna, the feed point position, and the size of conducting plane, the return loss bandwidth and the directivity can be controlled. The return loss bandwidth of $2.57 \%$ and the directivity of $4.34 \mathrm{dBi}$ are obtained, when the size of conducting plane is $0.245 \square$ ( $\square$ : wavelength) by $0.49 \square$, and the antenna height is $\square / 30$. The input impedance of the proposed antenna is compared with those of the conventional base-fed inverted $\mathrm{L}$ antenna and the base fed inverted $\mathrm{F}$ antenna. Although the directivity of base-fed inverted L antenna is almost same as that of proposed antenna, its input resistance becomes very low. In the base fed inverted $\mathrm{F}$ antenna, the return loss larger than $10 \mathrm{~dB}$ is not satisfied in the case of the antenna height less than $0.05 \square$.
\end{abstract}

Keywords: ILA, Low Profile Antenna, Return Loss, Unbalanced Fed, WIPL-D.

\section{Introduction}

The input impedance of horizontal dipole positioned very close to a perfect conducting plane becomes low due to the occurence of a metallic structure, and it approaches zero as the distance decreases toward zero [1 - 3]. An ultra-low profile dipole antenna, which is a horizontal dipole very closely positioned to an infinite conducting plane was proposed to solve the impedance matching problem [4]. A half wave-length dipole is excited at the offset points from its center, so that reasonable impedance can be attained even with a conducting plane in proximity to the dipole. The maximum gain is higher than that of a half-wave dipole with a quarter wavelength distance between the dipole and the reflector about $8.4 \mathrm{dBi}$. The return loss bandwidth greater than $10 \mathrm{~dB}$ is about $2 \%$. In order to realize ULPD, however, a $3 \mathrm{~dB}$ coupler and a $90^{\circ}$ phase shifter are needed. The applied unbalanced feed by the author to the ultra low profile inverted $\mathrm{L}$ antenna positioned very close on a rectangular conducting plane and analyzed numerically and experimentally [5]. We may call this antenna as "ULPIL antenna" for convenience. As a low profile antenna, the base fed inverted $\mathrm{F}$ antenna is well known [6 - 11]. The antenna with base fed inverted $F$ antenna in the case of the size of $0.245 \square$ have been compared to $0.49 \square$ [ 12]. In order to obtain the good return loss and the maximum directivity at the design frequency, many parameters such as the antenna height, the length of horizontal element, the feed point position and the size of conducting plane have to be optimized. In the previously reported references [5] and [12], the antenna parameters were not optimized.
In this paper, the ULPIL antenna on a rectangular conducting plane is analysed numerically and experimentally and the relation between its characteristics and antenna parameters is discussed. The base fed inverted $\mathrm{F}$ antenna is compared by the characteristics of ULPIL antenna. In the numerical analysis, the electromagnetic for antenna simulator WIPL-D based on the Method of Moments is used [13].

\section{Structure of proposed ULPIL antenna}

Figure 1(a) shows the structure of the proposed antenna located on a rectangular conducting plane. The size of conducting plane is pxp+pxm by pyp+pym. The mounted semi-rigid coaxial cable with the characteristics impedance of $50 \Omega$ on the conducting plane. The radius of the outer conductor is $1.095 \mathrm{~mm}$ and that of the inner conductor is $0.255 \mathrm{~mm}$, and PTEE (polytetrafluoroethylene) is filling the space within a coaxial cable [14]. This antenna consists of a horizontal arm in the y-direction and a small leg in the z-direction. The coaxial cable is extended behind ground plane. The generator is connected to the bottom end of coaxial cable. The inner conductor of the coaxial cable is extended from the end of outer conductor, that is, this antenna is excited at the end of outer conductor in the numerical analysis. The height of horizontal element is h. Figure 1(b) shows the conventional, base fed inverted $\mathrm{F}$ antenna. The design frequency is $2.45 \mathrm{GHz}$. The wavelength $\square$ at $2.45 \mathrm{GHz}$ is $122.45 \mathrm{~mm}$. Since the edge singularity of electromagnetic field affects the antenna characteristics, the edge effect is considered in the numerical calculation [13]. 


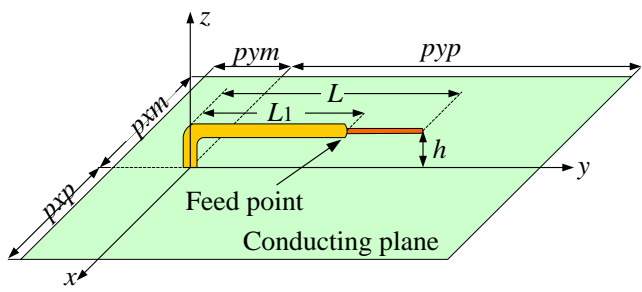

(a) ULPIL antenna

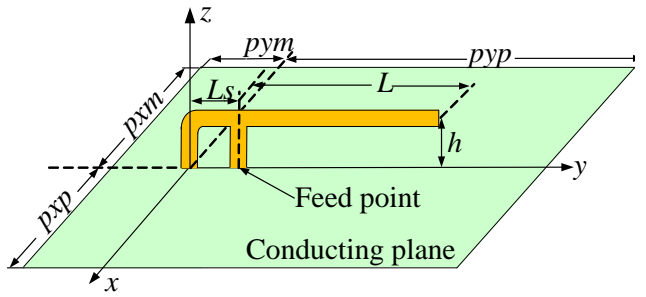

(b) Base fed inverted $\mathrm{F}$ antenna

Fig. 1: ULPIL antenna and base fed inverted $F$ antenna on a rectangular conducting plane.

\section{Result and discussion}

In this section, the relation between the return loss and directivity characteristics and the parameters of ULPIL antenna such as the antenna height $h$, the length of horizontal element $\mathrm{L}$, the feed point position L1, the width of conducting plane pxm = pxp, the length between the base point of antenna and the end of conducting plane pyp is discussed. The characteristics of ULPIL are also compared with those of the base fed inverted L antenna and the base fed inverted $\mathrm{F}$ antenna.

\subsection{Effect of antenna height $h$}

Table 1 shows the return loss bandwidth larger than $10 \mathrm{~dB}$ and the directivity for different antenna height $h$. The length of horizontal element $\mathrm{L}$ and the feed point position $\mathrm{L} 1$ are optimized so that the resonant frequency becomes to be $2.45 \mathrm{GHz}$. The fixed antenna parameters are as follows; $p x p=p x m=15 \mathrm{~mm}$, pym $=10 \mathrm{~mm}$, pyp $=44 \mathrm{~mm}$. Figure 2 show the current distribution on ULPIL antenna for different $\mathrm{h}$. As $\mathrm{h}$ becomes smaller the larger current flows on the conducting plane, since the mutual coupling between the inverted $\mathrm{L}$ antenna and the ground plane becomes stronger. Therefore the return loss bandwidth becomes narrower and the directivity becomes higher. When $\mathrm{h}=4 \mathrm{~mm}(\square / 30)$, the return loss bandwidth becomes $2.57 \%$ and the directivity of $4.34 \mathrm{dBi}$ is obtained. By adjusting the pyp, the directivity becomes higher compared with the result of the reference [5].

Table 1: Return loss and directivity of ULPIL antenna for different antenna height $h$.

\begin{tabular}{|c|c|c|c|c|c|c|}
\hline$h$ & $L$ & $L_{1}$ & \multicolumn{3}{|c|}{ Return loss bandwidth } & $\begin{array}{c}\text { Directivity at } \\
2.45 \mathrm{GHz}\end{array}$ \\
\hline \multicolumn{2}{|c|}{$[\mathrm{mm}]$} & $\begin{array}{c}\text { Lowest } \\
\text { freq. } \\
{[\mathrm{GHz}]}\end{array}$ & $\begin{array}{c}\text { Highest } \\
\text { freq. } \\
{[\mathrm{GHz}]}\end{array}$ & {$[\%]$} & {$[\mathrm{dBi}]$} \\
\hline 2 & 31.8 & 26.9 & 2.439 & 2.459 & 0.82 & 4.79 \\
\hline 4 & 31.0 & 22.6 & 2.417 & 2.480 & 2.57 & 4.34 \\
\hline 6 & 29.8 & 18.2 & 2.392 & 2.509 & 4.78 & 4.18 \\
\hline 8 & 28.3 & 14.2 & 2.386 & 2.545 & 6.49 & 4.01 \\
\hline 10 & 26.8 & 9.9 & 2.334 & 2.581 & 10.08 & 3.81 \\
\hline
\end{tabular}

pxm $=$ pxp $=15 \mathrm{~mm}$, pym $=10 \mathrm{~mm}$, pyp $=44 \mathrm{~mm}$

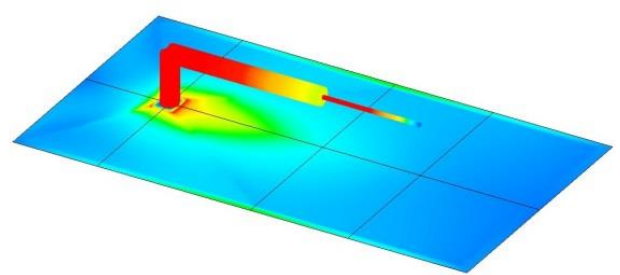

(a) $h=4 \mathrm{~mm}$

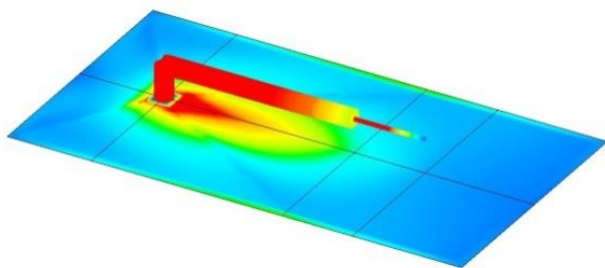

(b) $h=6 \mathrm{~mm}$

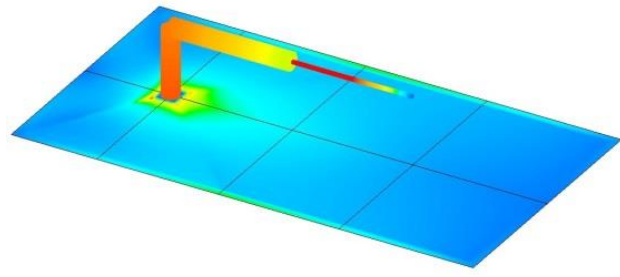

(c) $h=8 \mathrm{~mm}$

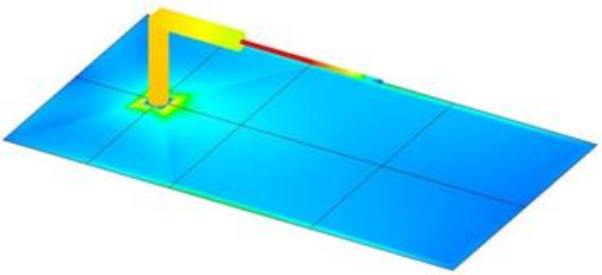

(d) $h=10 \mathrm{~mm}$

Fig. 2: Current distribution of ULPIL antenna. $p x m=p x p=15 \mathrm{~mm}$, pym $=$ $10 \mathrm{~mm}$, pyp $=44 \mathrm{~mm}$

\subsection{Effect of length of horizontal element $L$}

Figure 3 shows the input impedance characteristics of ULPIL for different L. $\mathrm{L} 1=22.6 \mathrm{~mm}, \mathrm{~h}=4 \mathrm{~mm}, \mathrm{pxm}=\mathrm{pxp}=15 \mathrm{~mm}$, pym $=10 \mathrm{~mm}$, and pyp $=44 \mathrm{~mm}$ are fixed. In the case of $\mathrm{L}=31 \mathrm{~mm}$, the resonant frequency becomes to be $2.45 \mathrm{GHz}$. In the figure, the input impedances at the design frequency of $2.45 \mathrm{GHz}$ are indicated by " $\mathrm{x}$ ". When $\mathrm{L}$ is $30 \mathrm{~mm}$, the input reactance becomes capacitive. On the other hand, when $\mathrm{L}$ is $32 \mathrm{~mm}$, the input reactance becomes inductive. This is easily explained by the transmission line theory [15]. The input reactance of the open circuited parallel line becomes capacitive if its length becomes shorter than a quarter wavelength. Figure 4 shows the reflection coefficient for different L. L1 is optimized so that the S11 becomes smallest at the resonant frequency in each case. The resonant frequencies in the case of $\mathrm{L}=30 \mathrm{~mm}, 31 \mathrm{~mm}$, and $32 \mathrm{~mm}$ are $2.535 \mathrm{GHz}, 2.45 \mathrm{GHz}$, and $2.375 \mathrm{GHz}$, respectively. The length of $\mathrm{L}$ becomes almost a quarter wavelength at each resonant frequency. This means that the resonant frequency can be adjusted by L. 


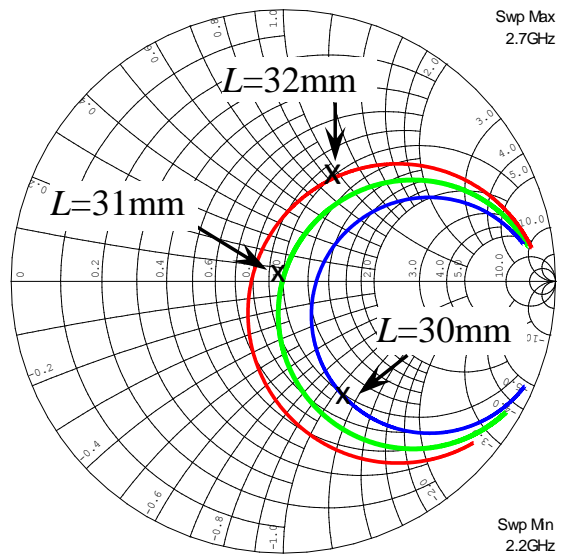

Swp Mn

Fig. 3: Input impedance characteristics of ULPIL antenna for different $L$. h $=4 \mathrm{~mm}, \mathrm{~L} 1=22.6 \mathrm{~mm}, \mathrm{pxm}=\mathrm{pxp}=15 \mathrm{~mm}, \mathrm{pym}=10 \mathrm{~mm}, \mathrm{pyp}=44$ $\mathrm{mm}$.

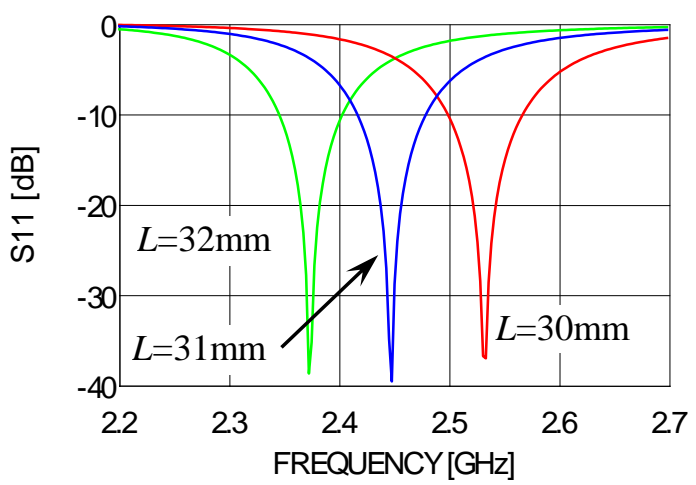

Fig. 4: S11 characteristics of ULPIL antenna for different $L$. L1 is optimized $. \mathrm{h}=4 \mathrm{~mm}, \mathrm{pxm}=\mathrm{pxp}=15 \mathrm{~mm}$, pym $=10 \mathrm{~mm}$, pyp $=44 \mathrm{~mm}$.

\subsection{Effect of feed point position $L_{1}$}

Figure 5 shows the calculated current distributions of ULPIL with $\mathrm{L} 1=22.6 \mathrm{~mm}$ and the base fed inverted $\mathrm{L}$ antenna. The input impedance is defined by the ratio of the impressed voltage and the feed point current. Therefore the input resistance becomes smaller, as L1 becomes smaller. The input impedance is $50 \square$ in the case of L1 is $22.6 \mathrm{~mm}$. That of base fed inverted L antenna is $4.06+\mathrm{j} 26.85 \square$. The directivity of ULPIL with $\mathrm{L} 1=22.6 \mathrm{~mm}$ and the base fed inverted $\mathrm{L}$ antenna is $4.34 \mathrm{dBi}$ and $4.86 \mathrm{dBi}$, respectively. Since the input impedance of the base fed inverted $\mathrm{L}$ antenna is mismatched to $50 \square$, the actual gain of it becomes low.

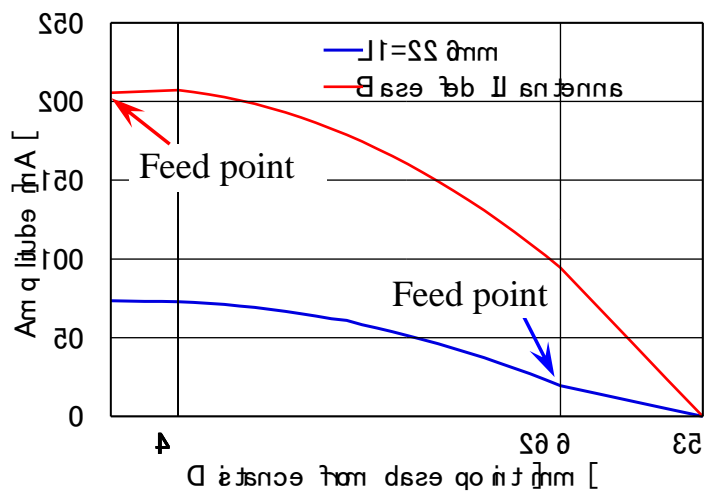

(a) amplitude distribution

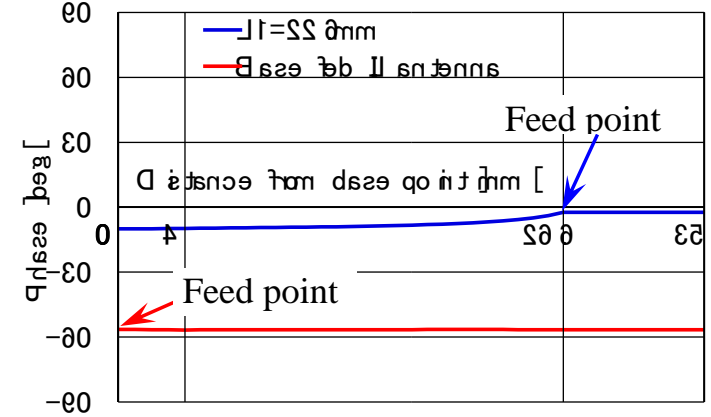

(b) Phase distribution

Fig. 5: Calculated current distribution at $2.45 \mathrm{GHz}$ for different $L_{1} . h=4$ $\mathrm{mm}, L=31 \mathrm{~mm}$, pxm $=$ pxp $=15 \mathrm{~mm}$, pym $=10 \mathrm{~mm}$, pyp $=44 \mathrm{~mm}$.

\subsection{Effect of width of conducting plane $p x p=p x m$}

Table 2 shows the return loss bandwidth and the directivity for different width of conducting plane $\mathrm{pxp}=\mathrm{pxm}$. The feed point position $\mathrm{L} 1$ are optimized by the length of horizontal element $\mathrm{L}$ so that the resonant frequency becomes to be $2.45 \mathrm{GHz}$. As the width of conducting plane becomes wider up to $30 \mathrm{~mm}$, the return loss bandwidth becomes narrower and the directivity becomes higher. The return loss bandwidth becomes wider and the directivity becomes lower following the changes width of the conducting plane becomes wider. In this antenna, as shown in Figure 2, the large current flows on the ground plane. This means that the current on the ground plane just under the horizontal element contributes to the radiation.

Table 2: Return loss and directivity of ULPIL antenna for different $p x p=$

pxm
\begin{tabular}{|c|c|c|c|c|c|c|}
\hline $\begin{array}{c}\text { pxp } \\
\text { pxp }\end{array}$ & $L$ & $L_{1}$ & \multicolumn{3}{|c|}{ Return loss bandwidth } & $\begin{array}{c}\text { Directivity at } \\
2.45 \mathrm{GHz}\end{array}$ \\
\hline \multicolumn{3}{|c|}{$[\mathrm{mm}]$} & $\begin{array}{c}\text { Lowest } \\
\text { freq. } \\
{[\mathrm{GHz}]}\end{array}$ & $\begin{array}{c}\text { Highest } \\
\text { freq. } \\
{[\mathrm{GHz}]}\end{array}$ & {$[\%]$} & {$[\mathrm{dBi}]$} \\
\hline 10 & 31.9 & 20.9 & 2.392 & 2.504 & 4.57 & 4.17 \\
\hline 15 & 31.0 & 22.6 & 2.417 & 2.480 & 2.57 & 4.34 \\
\hline 20 & 30.6 & 23.2 & 2.426 & 2.473 & 1.92 & 4.40 \\
\hline 25 & 30.4 & 23.5 & 2.432 & 2.471 & 1.59 & 4.48 \\
\hline 30 & 30.3 & 23.7 & 2.432 & 2.468 & 1.47 & 4.51 \\
\hline 35 & 30.1 & 23.5 & 2.432 & 2.469 & 1.51 & 4.47 \\
\hline 40 & 30.1 & 23.4 & 2.432 & 2.47 & 1.55 & 4.26 \\
\hline
\end{tabular}

$h=4 \mathrm{~mm}$, pym $=10 \mathrm{~mm}$, pyp $=44 \mathrm{~mm}$

\subsection{Effect of length of conducting plane pvp}

Figure 6 shows the return loss bandwidth and the directivity for different length pyp between the base point of ULPIL and the end of conducting plane. $\mathrm{pxm}=\mathrm{pxp}=15 \mathrm{~mm}$, and pym $=10 \mathrm{~mm}$ are fixed. The length $\mathrm{L}$ of horizontal element and the feed point position L1 are optimized so that the resonant frequency becomes to be $2.45 \mathrm{GHz}$.

As the antenna height $\mathrm{h}$ becomes higher, the directivity becomes worse although the return loss bandwidth becomes wider. This may be due to the angle subtended at the ground plane by the horizontal element of inverted antenna becomes small as $\mathrm{h}$ becomes higher. When pyp $=44 \mathrm{~mm}$ in the case of $\mathrm{h}=4 \mathrm{~mm}$, the directivity becomes maximum. Since the length of conducting plane becomes almost a half wavelength in this case, the large current flows on the conducting plane. 


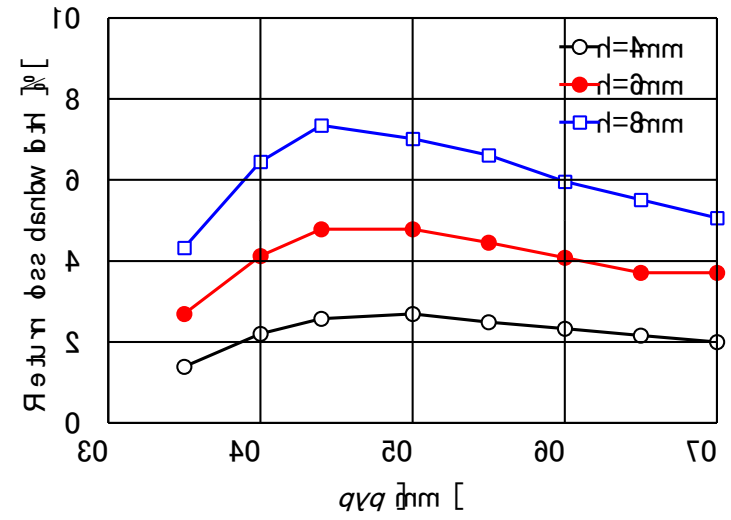

(a) Return loss bandwidth

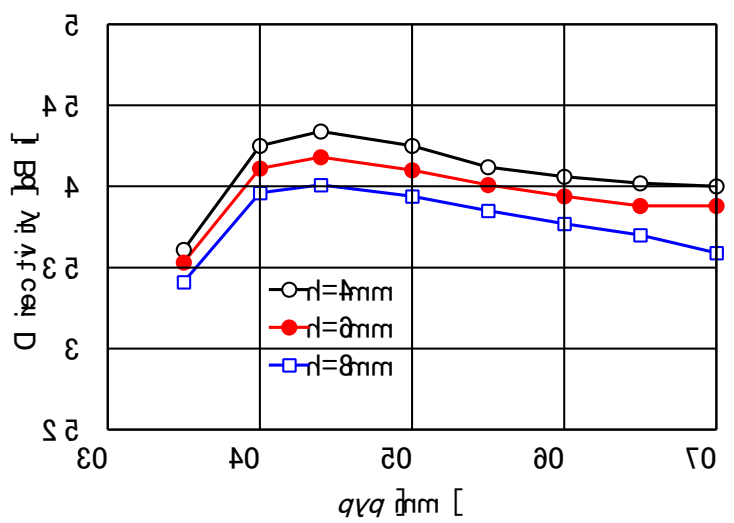

(b) Directivity

Fig. 6: Return loss bandwidth and directivity of ULPIL antenna for different $h . p x m=p x p=15 \mathrm{~mm}$, pym $=10 \mathrm{~mm}$.

\section{Comparison with base fed inverted $F$ an- tenna}

Table 3 shows the return loss bandwidth and the directivity of the base fed inverted $\mathrm{F}$ antenna for different antenna height $\mathrm{h}$ in the case of the length of short stub Ls $=3.3 \mathrm{~mm}$. In this section, the dimension and parameters of conducting plane are fixed as pxp = pxm $=15 \mathrm{~mm}$, pym $=10 \mathrm{~mm}$, and pyp $=44 \mathrm{~mm}$. Table 4 shows the return loss bandwidth and the directivity of the base fed inverted $\mathrm{F}$ antenna for different length of short stub Ls. In both tables, $\mathrm{L}$ and $\mathrm{L} 1$ are optimized so that the resonant frequency becomes to be $2.45 \mathrm{GHz}$. Figure 7 shows the input impedance characteristics of the base fed inverted $F$ antenna for different $h$. In the base fed inverted $\mathrm{F}$ antenna, the input impedance is adjusted by changing the element length $\mathrm{L}$ and short stub length Ls. From Figure 7, when the antenna height $\mathrm{h}$ is less than $7 \mathrm{~mm}$, the return loss larger than $10 \mathrm{~dB}$ is not satisfied even though the antenna length is adjusted. Figure 8 shows the input impedance characteristics of the base fed inverted $\mathrm{F}$ antenna for different Ls. Figure 8 indicates that the input impedance is not matched when the short stub length Ls becomes longer than $5 \mathrm{~mm}$.

Figure 9 shows the comparison of the return loss bandwidth and the directivity between ULPIL antenna and the base fed inverted $F$ antenna. When the height $\mathrm{h}$ of the base fed inverted $\mathrm{F}$ antenna is less than $7 \mathrm{~mm}$ (about $0.05 \square \square \square$, the return loss bandwidth larger than $10 \mathrm{~dB}$ is not satisfied even though the short stub is adjusted. Therefore, in Figure 9, data are not shown in the case of $h$ is less than $7 \mathrm{~mm}$. Figure 9 indicates that ULPIL antenna is very low profile and has higher gain compared with the base fed inverted $\mathrm{F}$ antenna.
Table 3: Return loss and directivity of base fed inverted $\mathrm{F}$ antenna for different $h$.

\begin{tabular}{|c|c|c|c|c|c|c|}
\hline$L s$ & $h$ & $L$ & \multicolumn{3}{c|}{ Return loss bandwidth } & $\begin{array}{c}\text { Directivity at } \\
2.45 \mathrm{GHz}\end{array}$ \\
\hline \multicolumn{3}{|c|}{$[\mathrm{mm}]$} & $\begin{array}{c}\text { Lowest } \\
\text { freq. } \\
\text { [GHz] }\end{array}$ & $\begin{array}{c}\text { Highest } \\
\text { freq. } \\
{[\mathrm{GHz}]}\end{array}$ & {$[\%]$} & {$[\mathrm{dBi}]$} \\
\hline 3.3 & 7 & 26.2 & 2.388 & 2.520 & 5.39 & 4.02 \\
\hline 3.3 & 8 & 25.6 & 2.353 & 2.556 & 8.29 & 3.92 \\
\hline 3.3 & 9 & 24.9 & 2.334 & 2.587 & 10.33 & 3.80 \\
\hline 3.3 & 10 & 24.3 & 2.312 & 2.610 & 12.16 & 3.69 \\
\hline
\end{tabular}

pxm $=$ pxp $=15 \mathrm{~mm}$, pym $=10 \mathrm{~mm}$, pyp $=44 \mathrm{~mm}$

Table 4: Return loss and directivity of base fed inverted $\mathrm{F}$ antenna for different $L$

\begin{tabular}{|c|c|c|c|c|c|c|}
\hline$L s$ & $h$ & $L$ & \multicolumn{3}{c|}{ Return loss bandwidth } & $\begin{array}{c}\text { Directivity at } \\
2.45 \mathrm{GHz}\end{array}$ \\
\hline \multicolumn{3}{|c|}{$[\mathrm{mm}]$} & $\begin{array}{c}\text { Lowest } \\
\text { freq. } \\
\text { [GHz] }\end{array}$ & $\begin{array}{c}\text { Highest } \\
\text { freq. } \\
{[\mathrm{GHz}]}\end{array}$ & {$[\%]$} & {$[\mathrm{dBi}]$} \\
\hline 3.3 & 10 & 24.3 & 2.312 & 2.610 & 12.16 & 3.69 \\
\hline 4.0 & 10 & 25.2 & 2.311 & 2.612 & 12.29 & 3.71 \\
\hline 5.0 & 10 & 26.5 & 2.314 & 2.603 & 11.80 & 3.73 \\
\hline 6.0 & 10 & 27.3 & 2.325 & 2.580 & 10.41 & 3.76 \\
\hline
\end{tabular}

pxm $=$ pxp $=15 \mathrm{~mm}$, pym $=10 \mathrm{~mm}$, pyp $=44 \mathrm{~mm}$

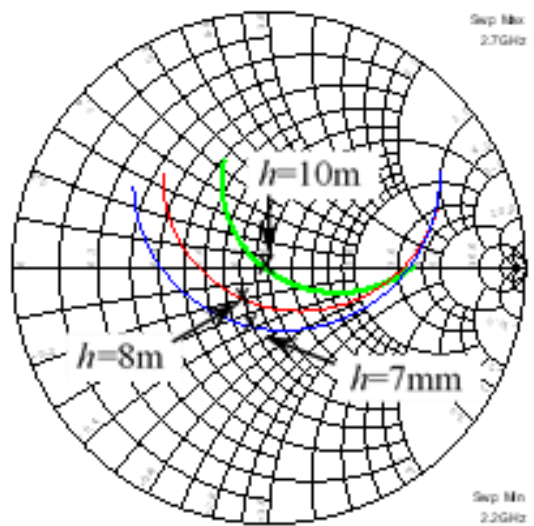

Fig. 7: Input impedance characteristics of base fed inverted $\mathrm{F}$ antenna for different $h . p x m=p x p=15 \mathrm{~mm}$, pym $=10 \mathrm{~mm}$, pyp $=44 \mathrm{~mm}, L s=3.3$ $\mathrm{mm}$.

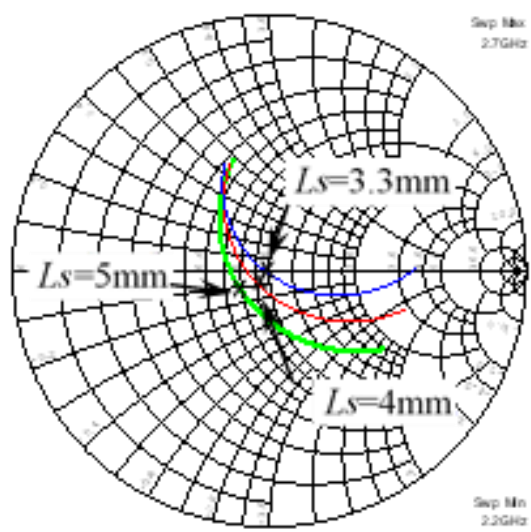

Fig. 8: Input impedance characteristics of base fed inverted $\mathrm{F}$ antenna for different $L s$. $p x m=p x p=15 \mathrm{~mm}$, pym $=10 \mathrm{~mm}$, pyp $=44 \mathrm{~mm}, h=10 \mathrm{~mm}$ 


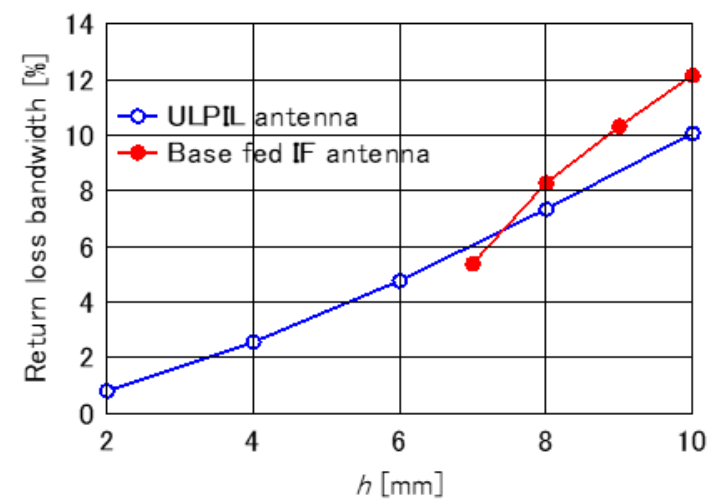

(a) Return loss bandwidth

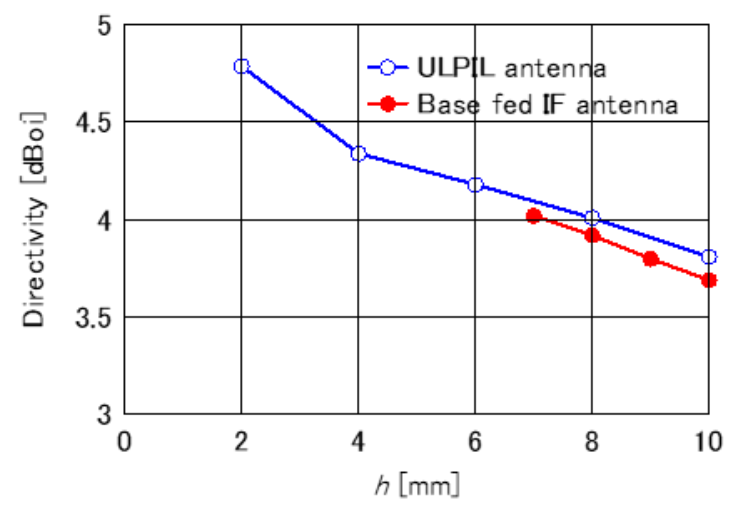

(b) Directivity

Fig. 9: Comparison of return loss bandiwidth and directivity between ULPIL antenna and base fed inverted $\mathrm{F}$ antenna. $p x m=p x p=15 \mathrm{~mm}$, pym $=10 \mathrm{~mm}$, pyp $=44 \mathrm{~mm}, L s=3.3 \mathrm{~mm}$.

\section{Comparison with measurement}

ULPIL antenna is fabricated and measured. Figure 10 shows the photograph of fabricated antenna [5]. The antenna parameters are as follows; $\mathrm{h}=4 \mathrm{~mm}, \mathrm{~L}=31.1 \mathrm{~mm}, \mathrm{~L} 1=22.6 \mathrm{~mm}, \mathrm{pxp}=\mathrm{pxm}=$ $15 \mathrm{~mm}$, pym $=10 \mathrm{~mm}$, pyp $=50 \mathrm{~mm}$. Figure 11 shows the calculated and measured return loss characteristics. The electric field radiation patterns at the frequency of $2.45 \mathrm{GHz}$ shown in Figure 12. In the case of an antenna on a small conducting plane, the leakage current may flow on the coaxial cable behind the conducting plane. In order to evaluate the influence of the leakage current on the coaxial cable behind the conducting plane to the radiation pattern, the clamp filter composed of the ferrite core is attached on the coaxial cable behind the ground plane [16]. Figure 13 shows the measured electric field radiation patterns of the antenna with the clamp filter at the frequency of $2.45 \mathrm{GHz}$. From Figure 12, the measured radiation pattern is slightly different with the calculated pattern in the backward direction. This difference becomes small when the clamp filter is attached on the coaxial cable. Therefore the leakage current on the coaxial cable may be small although the ground plane is small compared with the wavelength.

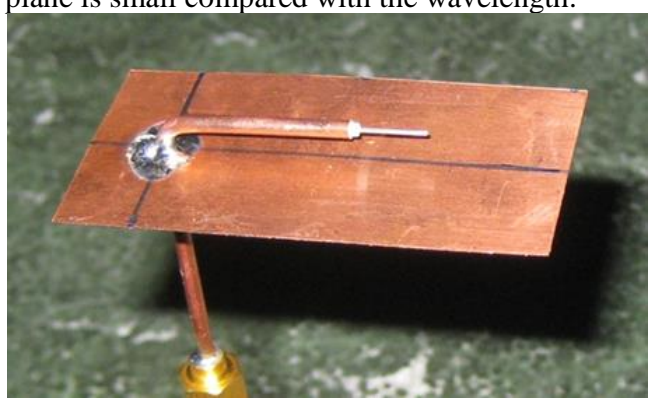

Fig. 10: Fabricated antenna.

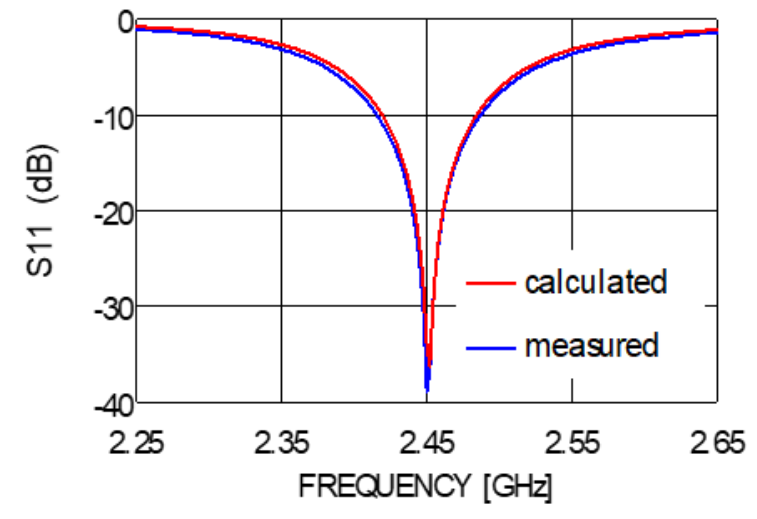

Fig. 11: Return loss characteristics of antenna. $h=4.0 \mathrm{~mm}, L=31.1 \mathrm{~mm}$, $L_{1}=22.6 \mathrm{~mm}, p x p=p x m=15 \mathrm{~mm}, p y m=10 \mathrm{~mm}$, pyp $=50 \mathrm{~mm}$.

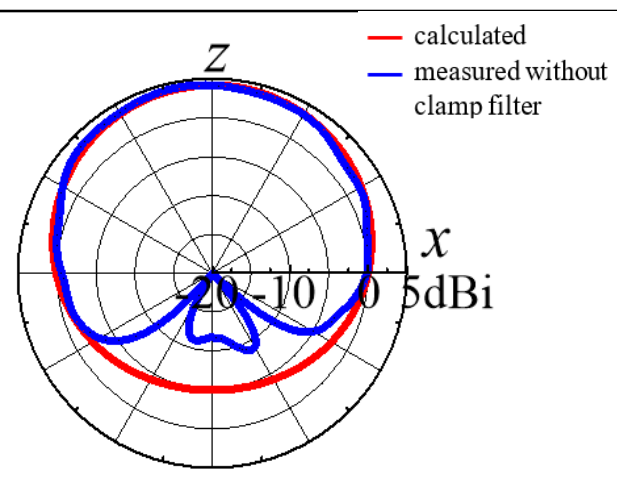

(a) $\square \square$ component $\mathrm{X}-\mathrm{z}$ plane

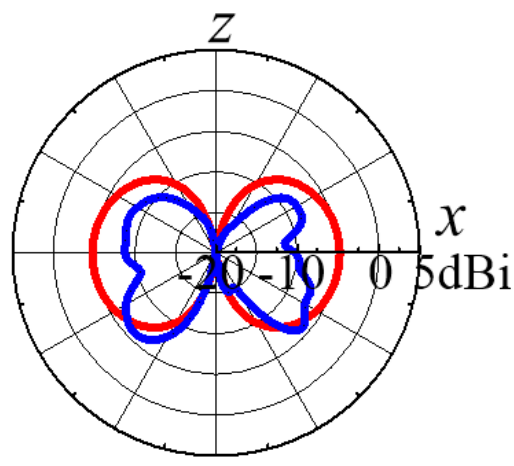

(b) $\square \square$ component $\mathrm{X}-\mathrm{z}$ plane

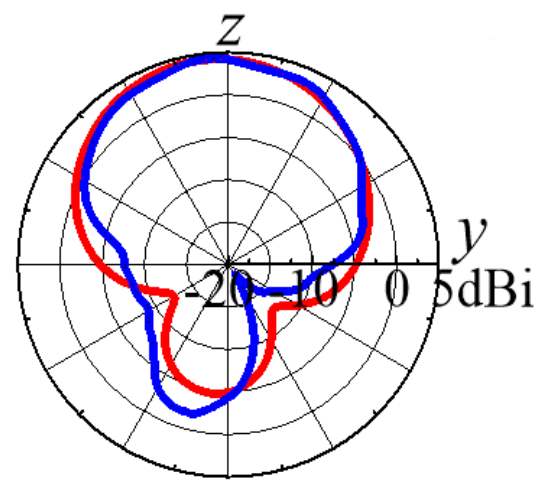

(c) $\square \square$ component y-z plane

Fig. 12: Electric field radiation patterns of ULPIL antenna at $2.45 \mathrm{GHz} . h=$ $4.0 \mathrm{~mm}, L=31.1 \mathrm{~mm}, L_{1}=22.6 \mathrm{~mm}, p x p=p x m=15 \mathrm{~mm}$, pym $=10 \mathrm{~mm}$, pyp $=50 \mathrm{~mm}$ 


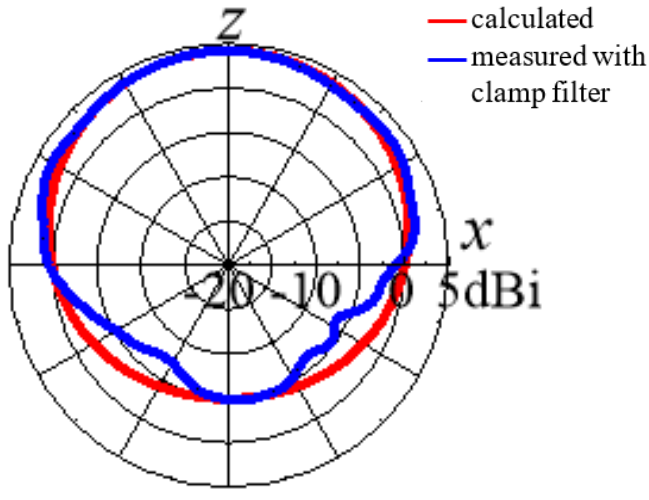

(a) $\square \square$ component $\mathrm{X}-\mathrm{Z}$ plane

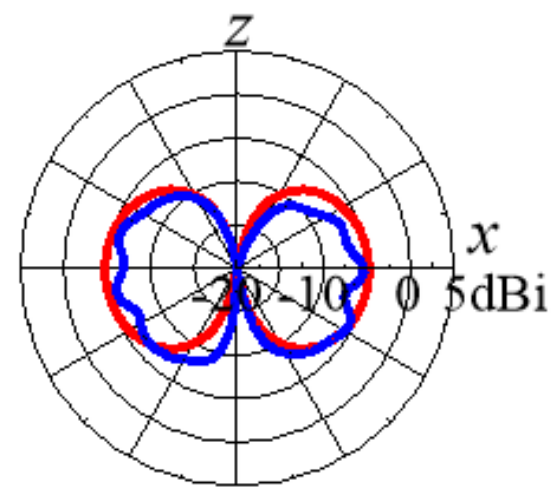

(b) $\square \square$ component X-z plane

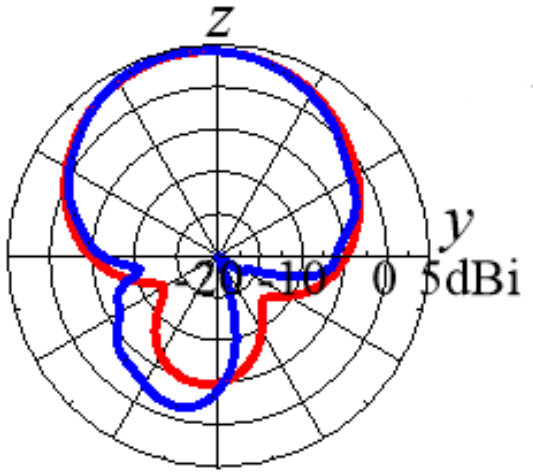

(c) $\square \square$ component y-z plane

Fig. 13: Electric field radiation patterns of ULPIL antenna at $2.45 \mathrm{GHz} . h=$ $4.0 \mathrm{~mm}, L=31.1 \mathrm{~mm}, L_{1}=22.6 \mathrm{~mm}$, pxp $=$ pxm $=15 \mathrm{~mm}$, pym $=10 \mathrm{~mm}$, рур $=50 \mathrm{~mm}$.

\section{Conclusion}

The proposed and analyzed ultra-low profile unbalanced-fed inverted $\mathrm{L}$ antenna on the rectangular conducting plane resonant frequency is decided by the length of the horizontal element and the impedance matching can be done by adjusting the position of the feed point.. The return loss bandwidth and the directivity are controlled by changing the antenna height and the size of rectangular conducting plane. When the size of conducting plane is $0.245 \square$ by $0.45 \square$ and the antenna height is $\square / 30$, the return loss bandwidth larger than $10 \mathrm{~dB}$ becomes $2.57 \%$ and the directivity is $4.34 \mathrm{dBi}$. The radiation characteristics of the base-fed inverted $\mathrm{L}$ antenna are almost same as those of proposed ULPIL antenna although the input resistance of base fed inverted L antenna becomes small. In this paper, the input impedance characteristics of the base fed inverted $\mathrm{F}$ antenna is also compared with the proposed ULPIL antenna. In the base fed inverted $F$ antenna, the input impedance is adjusted by changing the length of horizontal element and the short stub length. If the antenna height of base fed inverted $\mathrm{F}$ antenna is smaller than $0.05 \square$, the return loss larger than $10 \mathrm{~dB}$ is not satisfied. The proposed ULPIL antenna has high gain even though the antenna height is less than $0.05 \square$. The proposed antenna is applicable for the antenna for mobile terminal of the wireless communication.

\section{Acknowledgement}

The authors would like to express special thanks of gratitude to State Polytechnic of Malang for supporting this research.

\section{References}

[1] J. D. Kraus: Antennas. New York: McGraw-Hill, pp. 425-427 and 461-467, 1988

[2] C. A. Balanis: Antenna Theory Analysis and Design. New York: Wiley, pp. 175-180, 1997.

[3] S. A. Schelkunoff and H. T. Friis: Antennas Theory and Practice. New York: Wiley, 1952.

[4] A. Thumvicit, T. Takano and Y. Kamata: "Characteristics verification of a half-wave dipole very close to a conducting plane with excellent impedance matching", IEEE Trans. on Antennas and Propagat., vol.55, no.1, pp.53-58, Jan.2007.

[5] T. Yamashita and M. Taguchi: "Ultra Low Profile Inverted L Antenna on a Finite Conducting Plane", Proc. 2009 International Symp. on Antennas and Propagation, pp.361-364, Oct.2009.

[6] H. Attia, M. M. Bait-Suwalian and O. M. Ramahi, "Enhanced Gain Planar Inverted-F Antenna with Metamaterial Superstrate for UMTS Applications", Proc. PIERS., Cambridge, USA, pp. 494-497, 2010.

[7] Z. N. Chen, K. Hirasawa, "A New Inverted F Antenna with a Ring Dielectric Resonator", IEEE Trans. On Vehicular Technology, Vol. 48, No. 4, pp. 1029-1032, 1999

[8] D. Liu and B. P. Gaucher, "The inverted-F antenna height effects on bandwidth", Proc. IEEE Antenna Propag. Symp., Vol. 2A, pp. 367-370, 2005

[9] D. Liu and B. P. Gaucher, "A branched inverted-F antenna for dual band WLAN applications", Proc. IEEE Int. Symp. Antenna Propagations, Vol.3, pp. 2263-2626, 2004.

[10] S. Schulteis, C. Waldschmidt, C. Kuhnert and W. Wiesbeck, "Design of a Capacitively Loaded Inverted F Antenna for WirelessLAN Applications", Proc. International ITG-Conference on Antennas, 178:187-190, 2003.

[11] K. Ito and T. Hose, "Study on the characteristics of planar inverted $\mathrm{F}$ antenna mounted in laptop computers for wireless LAN", Proc. IEEE Int. Symp. Antennas Propag., Vol. 2, pp. 22-25, 2003.

[12] E. Rohadi and M. Taguchi, "Ultra low profile antenna for $2.45 \mathrm{GHz}$ wireless commnication", Proc. 2012 IEEE Int. Conf. on Communications, Network and Satellite , pp.103-107, 2012.

[13] "WIPL-D Pro v7.0 3D Electromagnetic Solver Professional Edition User's Manual”, WIPL-D, 2009.

[14] http://www.coax.co.jp/english/semi/219.html

[15] D. M. Pozar: "Microwave Engineering", Chapter 3, AddisonWesley Publishing Company, 1990.

[16] http://www.tdk.co.jp/tefe02/e9a15_zcat.pdf. 